Article

\title{
bricolage, poetics, spacing
}

\section{David Crouch}

Humanities Department, University of Derby, Derby, NG14 6AW Derbyshire, UK; d.c.crouch@derby.ac.uk

Received: 20 October 2017; Accepted: 23 November 2017; Published: 28 November 2017

\begin{abstract}
Contemporary concern for bricolage both transcends and supersedes de Certeau's important intervention that resituated the term as actions undertaken in everyday life. In particular, he engaged the notion of bricolage in ways that presented tactics, evasions, resistances, ruses and even tricks in his consideration of everyday life as practiced. Whilst these considerations may be read, as indeed he asserted, as 'making do', there are further possibilities of this term. For example, bricolage may be considered to 'occur'. In this we may take the anthropologist Hallam and Ingold's grasp of creativity as something in our bodily and mental response to situations, calm, anxious and otherwise; responding to the detail of a situation, a required or desired action.
\end{abstract}

Keywords: space; affectivities; atmosphere; feeling; bricolage; poetics; spacing

\section{Introduction}

Contemporary concern for bricolage both transcends and supersedes de Certeau's important intervention that resituated the term as actions undertaken in everyday life (de Certeau 1984). In this paper, the emergence of his ideas of bricolage are engaged in terms of their potentiality at the time, as well as reconsidered in the light of new readings of processes and practices of recent critical attention across a range of disciplines, in particular cultural geography and social anthropology. Their curiosity is their concern for the character, nuance and complexity of human life, folded into new, contemporary situations today.

Whilst de Certeau's considerations may be read, as indeed he asserted, as 'making do' (de Certeau 1984, op cit p. xviii), there are further possibilities of this term. For example, bricolage may be considered to 'occur'. In this we may take the anthropologist Hallam and Ingold's grasp of creativity as something in our bodily and mental response to situations, calm, anxious and otherwise; responding to the detail of a situation, a required or desired action (Ingold and Hallam 2007).

Bricolage may be about 'getting by', but it may also be able to render tackling situations, in however much detail and nuance they may assert, require, or happen. In these actions of bricolage, there are moments of occurrence, of potentiality and affect; atmosphere and becoming. Creativity is vital in affecting becoming, in becoming that is affective. Unlike familiar seasoned commentaries on creativity tracked along silicon valley (Thrift 2008), it is in the quiet cracks of everyday living, as an ongoing phenomenon, that creativity can happen, and happens; unplanned, unselfconsciously (Crouch 2010). The character of these moments, and their varying temporality, suggests an attention to the complexities and alertness of inquiry itself; the researcher as bricoleur acknowledging and engaging in a creative way to risk combining methods and collaborations.

In this revisioning of bricolage, which is nuanced rather than new, there is some necessity to engage contemporary complexity in the approaches to the character of living that brings into focus more than one discipline. The necessarily nuanced and complex character of living, of de Certeau's 'everyday life', which is fluid, uncertain, unfurling, and interrupted and thus resembles the atmospheres of bricolage, suggests John Law's argument of 'messiness' (Law 2005). Law was considering research methods, whose enriching through a constructive approach in the wielding of messiness in inquiry responded to a deepening awareness, in the earliest years of the current 
millennium, of the nuanced complexity, otherwise messiness, of our worlds. Messiness seems simply too pejorative. Whilst creativity is no equivalence of goodness, positivity or hope, it is at a minimum a skill, however perfected, in keeping life going. It contains also the potentiality of becoming. This complexity, perhaps more appropriate than messiness, deserves particular considerations that elide ideas of worlds, atmospheres and space(s). In ways, these terms and their ideas render new understandings of the working and power of bricolage.

\section{Occurrences of Bricolage}

Self-evidently, it is naïve to claim potentiality of creativity all the time, as at times it is blocked by the outward and internal influences in our own worlds; it may be stultified by others' rules and conduct - in which case, creative opportunity in everyday actions depends more or less on de Certeau's resistance in his panoply of tactics and responses. He pays particular attention to the feeling of 'ownership' of streets-ownership through engaging with those streets, perhaps to familiarity. He gives us agency in relation to the meaning of a street. This contrasts with the familiar, the almost habitual reading of space, only as the distance, fixed, to be carefully mapped and thereby closed. Turning away from this idea of fixity, he considers that 'space is a practiced place ... the street geometrically defined by urban planning is transformed into a space by walkers ... i.e., place constituted by a system of signs' (de Certeau 1984, op cit p. 118). Whilst de Certeau's reading is embedded in semiotics, it is also active in its walking practice. This acknowledgement of embodiment, tactility and feeling has of course greatly increased since the time he wrote that particular passage. From his apparent emphasis on semiotics, we might extend this meaning to embrace the nuance and complexity of walking, as well as the multi-sensuality, playing with memory, too. Anthropologist Kathleen Stewart would argue a swirl of atmosphere, affectivities, attunements and relations. (Stewart 2011).

Crucially, space is considered as a human process in spacing, rather than an abstract 'thing'. My focus is less on so-called broader contexts, culture, and so on, which simmer and provide background to feeling, significance, and meaning but do not determine. Instead, attention is on the contexts that humans render to space, along with the swirls of influences and affects in which we live, the other-than human and broader materiality; something fleshy with varying degrees of closure and open-ness over time.

Deleuze's and Guattari's ideas of the participatory character of spacing provide a leitmotif to this way of thinking, compounding the potentiality, and necessity of a rich bricolage in our inquiry (Deleuze and Guattari 2004, Crouch 2010). They used the word space in its verbal form, spacing. Whilst acknowledging the potentiality of overarching institutional power, producing striated space, like de Certeau's urban planners, they were interested in alternative production of space they called smooth space (de Certeau 1984, op cit). Space occurs also through lived practice and the relations of self, collectively, relating with others and amongst the spaces of practice in terms of affects and atmospheres. Arguably most geographical knowledge, for example, occurs in living, shaped, even suppressed by academic lines of thought. Individuals in their everyday lives participate in a wide variety of creativity; participating, affecting, not merely affected by. As Stewart remarks: "Things flash up-little worlds, bad impulses, events alive with some kind of charge" (Stewart 2007, p. 68). Stewart considers, in the liveliness of description, the affective character of living, not its emotions with that particularly psychological pull, often subdividing each one, but in feeling, inchoately gathered: for this discussion, how space feels matters as it makes relations and opens potentialities.

During the high points of postmodernism's proclaimed postmodernity, bricolage characterised the selective pick and mix of styles; fashion, architecture, music, haircuts: style that arises in a shared recognition of the significance of objects, of suggesting or establishing shared identity; exemplified in the early attention to style given by Dick Hebdige, in his startling book Subculture: the meaning of style (Hebdige 1979). Whilst Hebdige's work on style predated postmodernism, the latter took to new extremes the collision of assemblages of objects, for example across centuries of diverse architecture, that were understood as postmodern (in) style; 'smart' bricolage. Whilst some might regard, or read, 
particular style as messy, it is full of internal order, if order-in-disorder: yet its recognisability amongst 'it's' particular adherents renders style readable to others, hence no longer messy, yet investigators into an unfamiliar 'style' may need sensitive and responsive antennae to make their analysis. That bricolage perhaps exceeded its predecessors in reaching, in extremis, an erasure of categories, certainties and hierarchies of values; popular but not necessarily of a common culture (Bauman 1992). Decades after its demise, it is in and through other arenas, living, practices, desires and ideas that understandings and occurrences of bricolage emerge.

Indeed, disciplines over recent years articulate increasingly fruitful mutual, distinctive engagement. Such a shared orientation is exemplified in work around space, as a focus and critical provocation. Moreover of course it is necessary to reflect critically on the role of 'givens', what is often taken to be the sum of culture, that partly contextualise but do not dominate or determine but flicker across individuals' lives intersubjectively with affective power. Power emerges in the everyday living too, in what emerges as gentle politics. Our doings, relations, identities and negotiations also constitute and give character to the web or dynamic that is culture. Another commingling, another resistance or avoidance; another creativity occurs. Thus the liveliness of space is dynamic: iterative, felt, existing.

In confronting a more open and human (and beyond, the other-than human) character of space it is necessary, en route, to confront the old yet still-existing duality of place and space. These cornerstones of traditional geographical thought are part of the necessary multi-disciplinary reconfiguration of space. Ingold held on to a Heideggerian distinction of space-place, as one relatively external, the other something relatively fixed and enduring, close-up and situated in living and he seeks to avoid 'space' as operating in and through people's living: 'travellers make their way through the country, not through space, they walk and stand on the ground' (Ingold 2011, p. 145). Whilst the engagement of the world to which he refers is welcome, the rejection of space within our living creates questions of the human and space. Moreover, as Grosz interprets, people do not live in cities, but in networks of contacts, sites, memories and doings of lively interaction (Grosz 1999). The poetic philosopher Bachelard's attention focused on the gentle intensities of small spaces; cupboards, huts, nests, corners (Bachelard 1994). Bachelard's often indoor sites enabled him close intimacy with their form and the atmosphere that he felt; atmosphere beyond the physical and physiological, although they resonate too. They do, of course, avoid wider-in-the-world attention, however.

\section{Working through Space}

In working through these considerations, Stewart posits, feeling is important. Moreover, Erin Manning argues, alongside a further animation of space: "This feeling- with its proprioceptive, immediately linked to our sense of balance, to our ability to space space. We don't need to put our hands on the walls to feel them, or to touch the ground to know where it is. Touch crossed with vision and sound fields the environment, opening it to the relational multiplicity of movement, sensation, and space-time co-mingling." (Manning 2009, p. 49). Memory, across diverse and multiple spacetimes can be jogged into new affectivities in the performative, perhaps more than in the performance (Crouch 2003). Also numerous multiple outward contexts flicker and nudge; not as primary or privileged; our living, our ever-fluid memory, imagination and dreaming desires; this moment-these are all contexts that roll moment to moment and gather and break.

Rhythm is the emergent quality of felt intensity, a moving-toward of duration itself. Emma Cocker, stimulating art theorist, observes: 'Affect is not understood by reading about, rather reading is a constitutive practice within which affect is enacted, its flow is felt' (Cocker 2013, p. 23). The spirit of feeling, life and flow. In Cocker, Manning and Stewart, each in distinctive ways, enable a dialogical relationality in the way space is thought; in diverse multiple atmospheres, not scales or layering in the sense of consecutively settled strata, but sliced, dripping and chopped into each other, commingling perhaps.

My interpretations of the occurrence of space emerge from an early frustration with the ways in which especially geography deleted human life and its wider relations except for their statistical 
possibilities; distance triumphed over living; Euclidian space. It becomes possible to dig out something of the way in which we participate in how space occurs; fortunately wider geography has become increasingly mutually engaged with arts literature, including performance, anthropology and many other disciplines that have closer attention to human, and other-than human agents.

Space is addressed as problematic and not obvious, self-evident or resolved, but, like itself, its understanding is continually 'in the making', even here continuing beyond this chapter to prompting further enquiry. Space cannot adequately be considered as an afterthought of social and cultural processes; nor is it argued that space can be understood separate from our existence. The geographer Nigel Thrift claimed that 'Space comes in many guises: points, planes, parabolas; blots, blurs and blackouts' (Thrift 2006, p. 141). Space is relational, subjective and personal. Our understanding of it corresponds to that of Doreen Massey $(2005$, p. 9) for whom space is a relative 'product of interrelations' connected through identities and entities that provide it with directions, scale, meaning, borders and difference. According to her second preposition in For Space, it is a 'contemporaneous plurality ... predicated upon the existence of plurality'. Its existence, she argues, is contingent on those temporally moving relations that shape it by means of literature, metaphors, mathematics, art and poetry. Space is a 'simultaneity of stories-so-far'. It is in Massey's 'plurality' that our consideration emerges into bricolage's fluid contexts.

This approach delivers a space-character through the notion of multiple active participation in spacing, prompted by Kathleen Stewart's 'atmospheres':

“... attention to the charged atmospheres of everyday life ... how circulating forces are generated as atmospheres per se, how they spawn worlds, animate forms of attachment and detachment, and become the live background of living in and living through things. Writing through several small cases selected out of countless potentially describable moments and scenes in which the sense of something happening becomes tactile, I try to open a proliferative list of questions about how forces come to reside in experiences, conditions, things, dreams, landscapes, imaginaries, and lived sensory moments. How do people dwelling in them become attuned to the sense of something coming into existence or something waning, sagging, dissipating, enduring, or resonating with what is lost or promising? I suggest that atmospheric attunements are palpable and sensory yet imaginary and uncontained, material yet abstract. They have rhythms, valences, moods, sensations, tempos, and varied and changing lifespans. They can pull the senses into alert or incite distraction or denial." (Stewart 2011, p. 445).

Stewart gathers a bricolage, tracking energies and relationships in each component along the way. Like Barad, she draws in the matter of memory and its fluidity rather fixity of trajectory, gathering, commingling and splitting time: 'spacetimemattering ... spacetime enfolding ... . No overarching sense of temporality' (Barad 2010).

In A Space on the Side of the Road (Stewart 1996), Stewart addresses the feeling of living among poor individuals and families in the 'hollers' of West Virginia. In her writing, she wrests 'cultural representation free of the very claim to problem-solving absolute knowledge' (ibid., p. 23). She works from what local people speak of, netting the myriad components of their lives in open conversations and observations. She works their lived relational networks, from press observations, challenges they face, crises and hopes they endure, the feel of dust and the coping with others, government, memory of diverse and multiple pasts and more. She seeks across her work to capture the experienced real that, she feels and that we too feel, representational work has too often failed to reach, to evoke. Her attention is addressed to the felt process and practice of worlding: the way things occur through which individuals and collectivities make their lives and how it feels to do so; netting but never entrapping them in her writing or her reasoning, the myriad affects, or affective character that swirls into and among individuals' lives

In her book Literary Geographies, Sheila Hones writes of fiction as 'usefully understood as a geographic event, a dynamic unfolding collaboration happening in time and space' (Hones 2014, 
p. 32). The recent appearance of the journal Geohumanities embraces a wide range of concerns, from ethnographic fieldwork to territory and works at the intersections of geography and widely across the humanities. The British writer Ian Sinclair (2012, p. 85) writes of his personal journeys walking around, for example, the 'nether regions' off the London outer ring road or bypass, the M25. He discusses what he calls a 'map' as 'a very generalised form of a scrapbook or a cabinet of curiosities that includes written texts and a lot of photographs'. He identifies the growing interest across disciplines in literature and its poetic imagination: 'drawing on forms of memory, language, mapping, anthropology ... wanting to dissolve the boundaries that have held these to a rigid scholarly discipline' (ibid., p. 95). His maps-in-writing become evocative, expressive rather than representational, but move on in the reader to be both. Similarly, the 'maps' created in the project Parish Maps by the environmental charity Common Ground included a series of prompting maps by artists, painterly and graphic images of features, memories, moments performed in life. Over two thousand local communities, loose, closed or open, around Britain, among groups of individuals have worked together to make their own parish maps doing the same things: expressions of what matters to them in their lives that relates to where they live: spacing (Crouch and Matless 1996). With Sinclair, it is possible to say that maps of or as expressions of space, like everyday geographies, emerge in our practical ontologies, with the potential of being poetic and gently political, in an intimate way.

Our lived memory of visits to particular sites may be coloured, perhaps transformed, through later visits, whether to the same site and its remembered, unsealed spacetime or to other sites with which unconscious comparisons may be made. Similarly, different values become associated with different sites, and those values may with similar repetitions be mutually affective and affected. Our lived practice, along with the flicker of random representations, may merge or contrast each of these. Our efforts to order these myriad attachments or distortions may or may not succeed. Feelings of belonging and its longing become uncertain, and change colour, but some may hold. Loss may be unavoidable yet may be resuscitated. Memory emerges as a movable feast. Reflecting on Bachelard's philosophical musings upon his intimately drawn spaces, sociologists Metcalfe and Game (2008) identify the combination of 'I know this already' and 'this feels new', engaging pasts anew in the present. Our remembered, adjusted moments of heritage become embroiled in our presents. Campbell (2016) accounts of regionality-as-spacetimes is constituted in, for example, the writer Rebecca Solnit's deep personal reflections, the anthropologist Muecke's gathering and garnering of cultures' practices and almost memorial-making and Kathleen Stewart's anthropological fictive realism.

Rather than grasp meaning of processes of/in space as emergent principally between and across major scale assemblages, a close consideration of the affectivities swirling in everyday living renders an openness to the habitually-overlooked (especially, perhaps in geography, also cultural studies) significance of 'normal' human life in all its discontents. Reflection on these energies and affects amounts to a 'gentle politics' emergent in the power of individuals creatively to engage, experience, feel, create meaning, adjust and challenge their attitudes and values, and those of others. Spacing is creative and political.

\section{Conclusions, Provocations}

The complexity of the character of bricolage emerges in our examination of spacing: atmosphere, becoming, affectivities, and more. Space is activity, process, practice, performativites, stillness. In French, l'espace, spacing. Rather than grasp the meaning of processes of/in space as emergent principally between and across major scale assemblages, a close consideration of the affectivities swirling in everyday living renders an openness to the habitually-overlooked until recently, especially, perhaps in geography, however also considerably so across cultural studies. Our idea of space or place as constant is considered in relation to the steadying and shifting that occur in individuals' and collectivities' living. To capture some sense of these commingling events at work, it is necessary to engage place in the flow of understanding as merely a relative constitution of space and spacing: not fixity (i.e., place) in opposition to open fluidity (i.e., space-times) but an opening to affects, change, 
and security that explore the character of living spacetime through a number of threads that connect everyday living and our feeling and thinking. It serves as a means to articulate life in its negotiation, adjustment, disorientation and becoming. Space may come to feel relatively fixed yet remains open in possibility of further fluidity, even dramatic adjustment and loss.

There is, of course, a fullness of poetics at work and emerging here. This is found in the writing of Stewart, also of Manning. It is evident in the poetics of human living and relationality, which can work through spacing. Spacing affects poetic expression across numerous assemblages of things. In spacing, that includes landscape, one of spacing's expressive poetics (Crouch 2010).

Thus, you or I, the active individual, relationally with a whole web of evident liveliness that overspills classical and clinical confinement of process and practice. intimate lives, wide concerns and values; little gifts, oppression, small wonders; memory unsettling, discomfort and exhilaration of winds, bending, turning, even rolling over, feeling part of a collective practice. In all of the gaps between these things there is the spark of an affect, or rather of multiple, commingling or colliding affects, breaking, splitting, smoothing (Crouch 2017). Across this diverse gathering of voices it is possible to track the meshwork and expression of doing and feeling, and its expressive poetics, and also often overlooked gentle politics. This is how space occurs. Through the effect of affectivities belonging or disorientation can accompany our worlding, changeable as spacetimes. Lives and feelings feature prominently in the unpicking of spacing evoked in the words, mood, feelings, values and attitudes of the individuals who appear here, appear in life witnessed in participatory observation. It is easy to impose our thoughts upon what others say and do, move and reflect, and my guilt may be shared here. Yet it is in the intimate attention to what and how something is said and done, whispered and avoided, it becomes possible to offer a story of space in lives, affect and worlding that seems to do some justice to these testimonies. It becomes more possible to make sense of, and to conceptualise what often appears opaque (affect, atmosphere) that once seemed obvious.

Conflicts of Interest: The author declares no conflict of interest.

\section{References}

Bachelard, Gaston. 1994. The Poetics of Space: The Classic Look at How We Experience Intimate Places. Translated by Maria Jolas. Boston: Beacon Press.

Barad, Karen. 2010. Quantum entanglements and hauntological relations of inheritance: Dis/continuities, spacetime enfoldings and justice-to-come. Derrida Today 3: 240-68. [CrossRef]

Bauman, Zygmunt. 1992. Living on Borrowed Time. Cambridge: Cambridge Polity Press.

Campbell, Neil. 2016. Affective Critical Regionality. London: Rowman and Littlefield.

Cocker, Emma. 2013. Reading towards becoming casual. In Reading/Feeling. Edited by T. Baudoin, F. Bergholtz and V. Ziherl. Amsterdam: If I Can't Dance, pp. 21-24.

Crouch, David. 2003. Spacing, Performing, and Becoming: Tangles in the Mundane. Environment and Planning A 35: 1945-60. [CrossRef]

Crouch, David. 2010. Flirting with Space: Journeys and Creativity. Farnham: Ashgate, London: Routledge.

Crouch, David. 2017. Space, living, atmospheres, affectivities. In The Question of Space: Interrogating the Spatial Turn between Disciplines. Edited by Nuiwenhuis and Crouch. London: Rowman and Littlefield.

Crouch, David, and David Matless. 1996. Refiguring Geography: The Parish Maps of Common Ground. Transactions of the Institute of British Geographers 21: 236-55. [CrossRef]

de Certeau, Michel. 1984. The Practice of Everyday Life. Translated by S. Rendall. Berkeley: Berkeley University of California Press.

Deleuze, Gilles, and Felix Guattari. 2004. A Thousand Plateaus. London: Continuum.

Grosz, Elizabeth A. 1999. Thinking the New: Of Futures Yet Unthought. In Becomings: Explorationsin Time, Memory and Futures. Edited by E. Grosz. Ithaca: Cornell University Press, pp. 15-28.

Hebdige, Dick. 1979. Subculture: The Meaning of Style. London: Methuen.

Hones, Sheila. 2014. Literary Geographies: Narrative Space in Let the Great World Spin. New York: Palgrave Macmillan. Ingold, Tim. 2011. Being Alive: Essays on Movement, Knowledge and Description. London: Routledge. 
Ingold, Timothy, and Elizabeth Hallam. 2007. Creativity and Cultural Improvisation: An Introduction. In Creativity and Cultural Improvisation. Edited by I. E. Hallam and T. Ingold. Oxford: Berg, pp. 1-24.

Law, John. 2005. After Method: Mess in Social Science. London: Routledge.

Manning, Erin. 2009. Relationscapes: Movement, Art, Philosophy. Cambridge: The MIT Press.

Massey, Doreen. 2005. For Space. London: Sage.

Metcalfe, Andrew, and Ann Game. 2008. Potential Space and Love. Emotion, Space and Society 1: 18-21. [CrossRef]

Sinclair, Ian. 2012. Walking, Witnessing, Mapping: An Interview with Iain Sinclair. In Mapping Cultures: Place, Practice, Performance. Edited by Les Roberts. Basingstoke: Palgrave Macmillan, pp. 85-100.

Stewart, Kathleen. 1996. A Space on the Side of the Road: Cultural Poetics in an 'Other'. Princeton: Princeton University Press.

Stewart, Kathleen. 2007. Ordinary Affects. Durham: Duke University Press.

Stewart, Kathleen. 2011. Atmospheric Attunements. Environment and Planning D: Society and Space 29: 445-53. [CrossRef]

Thrift, Nigel. 2006. 'Space'. Theory, Culture E Society 23: 139-46.

Thrift, Nigel. 2008. Non-Representational Theory: Space, Politics, Affect. London: Routledge.

(C) 2017 by the author. Licensee MDPI, Basel, Switzerland. This article is an open access article distributed under the terms and conditions of the Creative Commons Attribution (CC BY) license (http:/ / creativecommons.org/licenses/by/4.0/). 